\title{
EPISTEMOLOGIA, CIÊNCIA E SABER NA EDUCAÇÃO EM/PARA OS DIREITOS HUMANOS NO BRASIL: UM OLHAR A PARTIR DO BEM VIVER
}

\section{EPISTEMOLOGY, SCIENCE AND KNOWLEDGE IN EDUCATION IN / FOR HUMAN RIGHTS IN BRAZIL: A LOOK FROM THE LIVING WELL}

\author{
Natália de Oliveira Melo - UFPE/Brasil \\ Timothy Denis Ireland - UFPB/Brasil
}

\begin{abstract}
RESUMO: O presente texto foi escrito diante do amplo cenário de violências humanas e ambientais e por isso busca analisar a educação em/para os Direitos Humanos à luz do Bem Viver. Tendo em vista a degradação ambiental ao qual chegamos no século XXI, acreditamos que procedimentos educativos pautados nos Direitos Humanos podem agregar à sociedade, pois qualquer modo de vida é sustentando por práticas educativas. Como objetivo geral colocamos: discutir como a educação em/para os Direitos Humanos pode contribuir para uma prática pautada no Bem Viver. E como objetivos específicos: compreender a educação em/para os Direitos Humanos no Brasil; identificar os desafios de uma prática de educação em/para os Direitos Humanos no atual cenário brasileiro. Para isso, estudamos através de uma abordagem qualitativa, bibliográfica, exploratória, vislubrando serem esses os melhores caminhos para uma pesquisa nas ciências sociais e humanas. Dessa forma, percebemos que a educação em Direitos Humanos pode forjar sujeitos individuais e coletivos que mudem as realidades de marginalização através de práticas de transformações e de resistências e que é um grande desafio procurar vivenciar práticas educativas pautadas em/para os Direitos Humanos no atual cenário brasileiro onde as situações de violências estão emerjindo e proliferando. Logo é imprescindível que as atuais práticas de educação se guiem pela defesa e promoção dos Direitos Humanos e da Natureza.
\end{abstract}

Palavras-chave: Educação. Direitos Humanos. Bem Viver

ABSTRACT: This text was written in view of the large scenario of human and environmental violence and therefore seeks to analyze education in / for Human Rights in the light of Living Well. In view of environmental degradation reached in 21 st century, we believe that educational procedures related to human rights can add to society, once any way of life is supported by educational practices. As a general objective we put: to discuss how education in / for Human Rights can contribute to a practice based on Living Well. And as specified objectives: to understand education in / for Human Rights in Brazil; to identify the challenges of an education practice in / for Human Rights in the current Brazilian scenario. For this, we studied through a qualitative, bibliographic, exploratory approach, considering these the best paths for research in social and human sciences. Thus, we realize that education in Human Rights can forge natural and legal individuals that change realities of marginalization through practices of transformations and resistances and that it is a great challenge to try to experience educational practices based on / for Human Rights in the Brazilian moment where situations of violence are

Educação, Psicologia e Interfaces, Volume 4, Número 3, p. 1-15, Julho, 2020.

ISSN: 2594-5343. DOI: 10.37444/issn-2594-5343.v4i3.259 
emerging and proliferating. Therefore, is essential current practices of education to be guied by the defense and promotion of Human and Nature rights.

Keywords: Education. Human rights. Living Well.

\section{INTRODUÇÃO}

É notório e preocupante a situação ambiental a qual nos encotramos. O presente séculos trouxe muitos avanços e muitos danos aos bens naturais, e essa segunda década do século XXI vem com alertas cada vez mais alarmantes que o nosso planeta não tem mais condições de sustentar o estilo de vida que nós humanos, ditos civilizados, estamos vivendo. A questão ambiental tem ganhado espaço nas dicussões sociais, políticas econômicas e acadêmicas. Estamos, enquanto sociedade nos dando conta (com exceções, claro) que precisamos rever nosso relacionamento com as outras formas de vida, logo, precisamos nos reeducar em nossas práticas cotidianas.

Nesse sentido de novas formas de lidar com o meio ambiente numa nova prática de vida, nossos estudos apontam o Bem Viver ou "Buen Vivir" em sua língua original. Esse conceito emerge das tradições indígenas, que na expressão quíchua pode- se ler como "Sumak Kawsay”. Sua tradução se aproxima com “viver bem”, e que na América Latina vem se popularizando como Buen Vivir. Em nossos textos nos utilizaremos daqui por diante da nomenclatura Bem Viver. Em alguns países como Equador e Bolívia esse conceito é mais que uma rede de pensamentos e se direcionou para suas respectivas constituições de 2008 e 2009, como também de políticas públicas que buscam implementar as mencionadas constituições. O Bem Viver transcende conceitos teóricos. É mais. É estilo de vida, é uma relação harmônica entre ser humano e mundo, onde ambos estão conectados e ambos vivem bem nessa relação, como Fernández (2016) coloca.

Pensando nesse caminho de reeducação para uma nova concepção de prática de vida, que valorize a vida, percebemos que o Bem Viver em muito dialoga com a educação, especificamente a educação em e para os Direitos Humanos (EDH), no contexto da América Latina. Pois o Bem Viver trata-se de uma vivência própria desse contexto geográfico. A educação em e para os Direitos Humanos em sua essência busca

Educação, Psicologia e Interfaces, Volume 4, Número 3, p. 1-15, Julho/Setembro, 2020.

ISSN: 2594-5343. DOI: 10.37444/issn-2594-5343.v4i3.259 
Epistemologia, ciência e saber na educação em/para os Direitos Humanos no Brasil: um olhar a partir do Bem Viver

desenvolver caminhos no qual todo e qualquer ser humano tenha uma vida digna, educando assim para uma cultura em Direitos Humanos, como Silveira (2007) aborda.

Nessa perspectiva então, trazemos a importância dos estudos que estamos desenvolvendo, que é pensar em práticas educativas que valorizem e preservem a vida, para além da vida do ser humano, mas a vida da natureza. E assim, mediante nossos estudos colocamos como questão problema a seguinte indagação: Como a educação em/para os Direitos Humanos pode contribuir para uma prática pautada no Bem Viver? Para isso colocamos como objetivo geral: Discutir como a educação em/para os Direitos Humanos pode contribuir para uma prática pautada no Bem Viver. E para alcançar o que nos propomos colocamos como objetivos específicos: Compreender a educação em/para os Direitos Humanos no Brasil; Identificar os desafios de uma prática de educação em/para os Direitos Humanos no atual cenário brasileiro

\section{MATERIAL E MÉTODO}

O presente texto é um capítulo fruto do nosso trabalho de dissertação defendido no Programa de Pós-Graduação em Direitos Humanos (PPGDH) na UFPB. Trata-se de uma abordagem qualitativa segundo Appolinário (2012) na qual busca-se estudar as interações e os fenômenos sociais em virtude da própria sociedade. Buscamos estudar a educação em Direitos Humanos no Brasil, seus desafios atuais e sua postura frente às questões ambientais porque tais elementos estão inseridos nos atuais dilemas que envolvem a humanidade. Também se trata de uma pesquisa bibliográfica onde nesse tipo de pesquisa buscamos estudar os conceitos, as teorias, como também os rever, analisálos, interpretá-los e crticá-los a fim de levar à reflexão. Nos apoiamos em Barros e Lehfel (2007) quando estes autores nos dizem que na pesquisa bibliofráfica os estudos se apoiam em materiais científicos que já existem para continuarem as reflexões acerca do objeto de estudo.

Nossos estudos também têm caráter exploratórios, pois buscam levantar um conjunto de informações acerca da educação em para os Direitos Humanos no Brasil sob a perspectiva do Bem Viver, das questões ambietais. Marconi e Lakatos (2017) nos dizem que os estudos exploratórios têm essa função de incialmente colher informações sobre

Educação, Psicologia e Interfaces, Volume 4, Número 3, p. 1-15, Julho, 2020.

ISSN: 2594-5343. DOI: 10.37444/issn-2594-5343.v4i3.259 
seu objeto de estudo e posteriormente fazer análises como também inferências sobre as questões estudadas.

Como técnica de coleta de dados colocamos como grande área a educação em para os Direitos Humanos no Brasil, logo colheremos e exploraremos os conceitos que se tem estudado do nosso objeto e as analisaremos à luz do Bem Viver. Para a análise de dados seguiremos o caminho proposto por Minayo (1994), da técnica da hermenêutica dialética, onde o ciclo da pesquisa se inicia pela fase exploratória, que trata-se do recolhimento de todo material disponível que aborda o tema, depois o recorte empírico, que trata-se de direcionar a discussão, e por fim o tratamento do material recolhido.

\section{RESULTADOS E DISCUSSÃO}

Apesar do Bem Viver ser um conceito em emergência nos estudos acadêmicos, ele próprio não é novo. É preciso reconhecer que esta ideologia de vida é parte do modo de viver indígena, e que somente agora, em meados do século XXI que nossa modernidade atentou para o mesmo. Enquanto nós, através dos nossos estudos, estamos iniciando as pesquisas sobre o Bem Viver, para os índios este conceito está intrínseco, e assim para eles é normal cultivar um estilo de vida de harmonia com os diversos tipos de vida. A vida é o elo, é o que precisa ser preservado em toda sua magnitude e importância. No entanto, ao colocar essa relação harmoniosa entre povos indígenas e natureza não queremos romantizar essa relação, apenas trazer para o presente texto a diferente relação que esse povo desenvolve com a natureza.

Quando pensamos em Bem Viver, por se tratar de um termo em ascendência no campo acadêmico algumas questões são postas. Há quem pergunte: trata-se de uma ideologia, de um paradigma, ou de uma teoria? São muitas as problemáticas que rodeiam o Bem Viver. No entanto, no intuito de melhor percorrer o caminho de estudos que nos propomos, concordamos com Larrea (2014) quando esta coloca que o Bem Viver se trata de uma ideia mobilizadora, que através da vivência prática incentiva um estilo de vida pautado na harmonia. Além de ser essa ideia mobilizadora, trata-se também de um artefato. No Dicionário Houaiss da Língua 
Epistemologia, ciência e saber na educação em/para os Direitos Humanos no Brasil: um olhar a partir do Bem Viver

Portuguesa (2001), encontramos que artefato é uma produção humana gerida para um fim prático oriundo em um determinado período histórico. O Bem Viver é fruto de criação humana, por isso um artefato, que busca uma vida boa para todas as formas de vida, por isso uma ideia mobilizadora.

\subsection{O que é a educação em/para os Direitos Humanos no Brasil}

A educação em e para os Direitos Humanos no Brasil se desenha de forma particular, pois tem uma especial ligação com os movimentos sociais. É sem dúvida fruto do engajamento de grupos que buscavam efetivar os Direitos Humanos nas práticas educacionais, sendo estas formais e não formais. Este elemento merece destaque, pois o caminho dessa educação não se inicia por leis, decretos ou programas para assim chegar nas realidades educacionais. É justamente o caminho inverso, mediante a vivência, a luta e o engajamento de grupos de profissionais e militantes, pela necessidade de se buscar uma educação que vivenciasse os Direitos Humanos é que se constroem as leis, decretos e programas que hoje estão em vigência. Concordarmos com Rodino (2016) quando esta coloca que as conquistas dos Direitos Humanos não são fruto da bondade do Estado, e sim fruto de muita luta e engajamento, e nesse sentido, a educação em e para os Direitos Humanos faz parte do resultado da luta dos movimentos sociais: é antes de tudo, decorrência de muito engajamento e planejamentos por parte de pessoas que buscavam (e buscam) uma educação direcionada para os Direitos Humanos e pelos Direitos Humanos.

Partindo dessas colocações básicas é importante mencionar: mas de qual educação em e para os Direitos Humanos no Brasil estamos falando? Trata-se de uma questão complexa, mas que merece a devida posição de destaque no presente texto. Quando pensamos em educar para e em Direitos Humanos não colocamos apenas os meios de educação formais, educar em e para os Direitos Humanos assume uma postura muito mais ampla que uma disciplina:

A educação em direitos humanos socializa uma concepção abrangente e de universalidade, daí a sua transversalidade, que não se circunscreve a nenhum campo disciplinar específico, não pertence a nenhuma área do conhecimento exclusiva. (SILVEIRA, 2014, p. 85).

Pensaremos então numa educação que se dê pelo viés dos Direitos Humanos

Educação, Psicologia e Interfaces, Volume 4, Número 3, p. 1-15, Julho, 2020.

ISSN: 2594-5343. DOI: $10.37444 /$ issn-2594-5343.v4i3.259 
através da ação. E como nos diz Silveira (2007), a educação em Direitos Humanos, trata-se de procedimentos de socializações de uma cultura em Direitos humanos, educando os sujeitos (individuais e coletivos) em processos permanentes para a defesa e promoção dos Direitos Humanos. Educar em e para os Direitos Humanos é ação, ação que precisa de seres humanos interagindo para que esta possa acontecer, para que os procedimentos de socialização de uma cultura em Direitos Humanos possam ocorrer. Tais procedimentos não se desenharão sempre por caminhos pacíficos e harmoniosos. O conflito estará presente nos procedimentos de socialização que se guiam por uma educação em Direitos Humanos.

Educar em e para os Direitos Humanos é ter essa sensibilidade para o que é coletivo, pois somos seres que estão inseridos em diversas coletividades. Não faria sentido então vivenciar uma educação em e para os Direitos Humanos que não se atentasse para as questões que tocam as diversas coletividades. Alguns elementos devem estar bem esclarecidos para que a educação em e para os Direitos Humanos se dê de maneira significativa. Candau e Sacavino (2010) colocam e explicam esses elementos. O conhecimento, que deve ser construído de forma plural; a aprendizagem, que deve se guiar pelos objetos da realidade; e o ensino, que se trata de processos desafiadores. Para que tais sujeitos busquem uma vivência nos Direitos Humanos se faz necessário um importante elemento: o conhecimento.

Educar em e para os Direitos Humanos valorizando o conhecimento e a criticidade contribuirá para a formação de sujeitos emancipados e autônomos, sendo esse um pressuposto básico da educação, como Viola e Pires (2016) nos dizem. Sujeitos emancipados são aqueles sujeitos livres e responsáveis por suas escolhas e sujeitos autônomos são aqueles capazes, que têm condições de fazer suas escolhas. Contribuir na construção de sujeitos capazes, livres e responsáveis por suas decisões é um dos objetivos da educação em e para os Direitos Humanos. É importante deixar claro tais princípios norteadores da educação em e para os Direitos Humanos porque nem todo processo educativo que se diz adepto a essa corrente, de fato a segue na concretude dos fatos. Os processos educativos podem ser contraditórios e contrários aos princípios dos Direitos Humanos, pois existem processos educativos que não educam para os Direitos Humanos, que não buscam para seus sujeitos uma vida de experiências dos Direitos Humanos, e essa vida para os Direitos Humanos, que 
Epistemologia, ciência e saber na educação em/para os Direitos Humanos no Brasil: um olhar a partir do Bem Viver

Carbonari (2016, p. 256) relata, é a: "vida boa, a vida com direitos, é o que espera e deseja a educação em direitos humanos". Esse é o objetivo principal e norteador da educação que se guia para e pelos Direitos Humanos: que seus sujeitos vivam uma vida digna, uma vida dos Direitos Humanos.

Assim, enxergamos a educação em Direitos Humanos em mais uma de suas possibilidades, sendo espaço de construção de sujeitos políticos. Nessa perspectiva não podemos permitir que restrinjam a educação em Direitos Humanos a uma educação em valores, é preciso expor seu caráter político, sua possibilidade (poderíamos até ousar em dizer característica fundamental) de instrumento politizador dos sujeitos, como Candau (2007) nos mostra. A partir do momento em que a educação em Direitos Humanos se propõe a contribuir na construção de sujeitos que busquem mudanças nas realidades que os cercam, essa assume um compromisso político. É inevitável. Contribuir na formação de sujeitos emancipados e autônomos é também contribuir na formação de sujeitos políticos.

Tal questão trata-se de mais um ponto acerca da relevância da educação em e para os Direitos Humanos, especialmente na América Latina e no nosso caso em particular, o Brasil. Colocamos o contexto da América Latina porque em muito dialoga com o cenário de construção no Brasil. E no cenário de América Latina, temos a Educação Popular ${ }^{1}$, que é uma vivência educacional e um conceito próprio latinoamericano. É resultado, como diz Paludo (2006) da história do continente associada aos processos sociais culturais e políticos da América Latina. Ideia base que emergiu dos pensamentos do escritor brasileiro Paulo Freire com suas obras revolucionárias que estão embasadas em práticas libertadoras e humanistas. A educação popular se concretiza em práticas humanas que visem uma sociedade dos Direitos Humanos, uma sociedade que todos possam desfrutar dos seus plenos direitos, sem marginalizações, sem opressões e sem segregações.

A vontade por se viver em uma sociedade que garanta, proteja e promova os direitos, torna- se coletiva. Logo, o interesse por se educar em e para a garantia, proteção e promoção desses direitos também é coletivo. E enquanto coletividade é importante valorizarmos e incentivarmos práticas educativas que se desenhem pelo viés aqui exposto, compreendendo que o desejo por uma sociedade dos Direitos Humanos que valorize a vida de maneira livre, deve ser o horizonte a ser buscado e

Educação, Psicologia e Interfaces, Volume 4, Número 3, p. 1-15, Julho, 2020.

ISSN: 2594-5343. DOI: 10.37444/issn-2594-5343.v4i3.259 
alcançado por toda uma humanidade, num processo constante.

\subsection{Desafios da educação em/para os Direitos Humanos no Brasil}

A educação em Direitos Humanos não é um projeto acabado. Esta funciona como um norte sem dizer com precisão qual o ponto. Não há garantias de que todo caminho percorrido pela educação em Direitos Humanos terá o mesmo resultado, o mesmo fim, pois as subjetividades e singularidades são elementos importantes e relevantes no processo de se educar em e para os Direitos Humanos. A questão que envolve o individualismo que existe nessas diversas subjetividades se configura como um dos desafios de se educar em e para os Direitos Humanos na atualidade. Perceber essa linha tênue entre um subjetivismo existente e relevante com um individualismo perigoso e isolador (beirando o egoísmo) é um dos elementos que merecem atenção, pois segundo Tosi (2017), esse subjetivismo faz parte da nossa modernidade, porém é perigoso para fundar uma sociedade mais justa.

É preciso se educar para o respeito de cada indivíduo, através de sua subjetividade, singularidade e liberdade, mas também se educar para a responsabilidade do indivíduo para com o coletivo no qual este está inserido. Pois: "responsabilidade social e pessoal constitui uma noção fundamental na educação em direitos humanos" (REARDON, 2007, p. 74). Contribuir para a construção de sujeitos de direitos é também, e indiscutivelmente, fomentar sujeitos responsáveis. E no atual contexto que estamos inseridos se faz mais que necessário processos de educação em que a noção de responsabilidade seja alimentada. O sentimento de coletivo, de pertencimento e de deveres para com o coletivo é um elemento que precisa ser fortalecido em nosso cenário político, social e cultural atual. Precisamos construir uma sociedade onde a igualdade seja parâmetro ético e indispensável. Somos, nas nossas diferenças, iguais. E tal noção de igualdade acontece pelo caminho de se pensar em comunidade.

A necessidade de se educar em e para os Direitos Humanos no Brasil hoje passa necessariamente por dois caminhos: o de acesso ao direito da educação e o fortalecimento da democracia através desse acesso. Só será possível que a sociedade se posicione e reivindique seus direitos, se a mesma tiver consciência da existência de tais direitos. A consciência passa pelo acesso à educação. Acesso à educação, no 
Epistemologia, ciência e saber na educação em/para os Direitos Humanos no Brasil: um olhar a partir do Bem Viver

entanto, não quer dizer necessariamente nível de consciência. Para além do acesso à educação é interessante uma proposta educativa que se faça pela conscientização, para que as pessoas possam estar aptas para reivindicarem seus direitos, Lima e Silveira (2017. p. 49) conotam que "educar em direitos humanos é fundamental porque é tanto uma garantia de que o direito à educação se materialize, quanto salvaguarda que, por meio desse direito, seja aperfeiçoada e protegida a democracia num país".

É uma postura contra hegemônica. A educação em e para os Direitos Humanos em cenários marginais, em contextos onde é preciso mais resistir do que muitas vezes avançar, a postura que se assume é contra uma ideologia que não valoriza os Direitos Humanos e não tem interesse em avançar em conquistas sociais. Essa postura contra hegemônica, segundo Silveira (2007), se desenvolve entre o sistema que existe e o sistema que se espera. Existe assim uma grande inconformidade com o cenário atual e, ao mesmo tempo, um horizonte de conquista muito bem desenhado - onde se espera chegar. E nesse processo de chegar nesse ponto, vai-se resistindo e lutando contra o que existe, através de procedimentos de socialização que se baseiam em pensamentos insurgentes, pensamentos de lutas e resistência.

É preciso força para se resistir. A resistência não é neutra nem aleatória, muito menos sem sentido. Há um motivo (vários, aliás), para se resistir, para se colocar numa posição contrária ao que está posto. Podemos colocar dois motivos básicos para que a educação em e para os Direitos Humanos no Brasil necessita guiar-se pela resistência. O primeiro é que não podemos permitir retrocessos e o segundo e que não podemos permitir repetições de agressões aos Direitos Humanos. Lima e Silveira (2017, p. 54) abordam sinteticamente esse ponto:

Tendo esses objetivos em mente, no contexto sociopolítico e cultural em que nos encontramos, será necessário, também, que o olhar do(a) estudante, do(a) docente, do(da) cientista esteja sempre voltado ao retrovisor da história, para que não admitamos recuos drásticos e perda de direitos que foram conquistados por alto preço, bem como a repetição do passado autoritário, especialmente no Brasil. Torna-se, ainda, imperativo que estes mesmos olhos vislumbrem a dignidade da pessoa humana como tangível e plena em um futuro breve.

Educação, Psicologia e Interfaces, Volume 4, Número 3, p. 1-15, Julho, 2020.

ISSN: 2594-5343. DOI: 10.37444/issn-2594-5343.v4i3.259 
O retrovisor da história é a força mobilizadora da educação em e para os Direitos Humanos no Brasil. Parece trágico imaginarmos que existem possibilidades de regressarmos tanto. Mas há. Infelizmente há. As ações desenvolvidas atualmente pelos diversos segmentos nos mostram e nos dizem que essa possibilidade é real, que podemos regressar a práticas onde os direitos não eram respeitados, e mais que isso, eram absurdamente violentados. Não podemos regressar. Não podemos reviver um passado tão cruel e pesado. Não temos mais forças para revivermos uma história tão sangrenta. Então, canalizam-se as atenções para práticas que vão de encontro a essas possibilidades. Busca-se viver uma educação em Direitos Humanos que crie condições de sairmos de situações que nos lembrem de alguma forma esse passado, que não é para ser esquecido. Pelo contrário, é para ser lembrado com toda força, para não ser repetido sob nenhuma forma.

Um ponto também de fundamental importância para a educação em e para os Direitos Humanos no Brasil, é a educação para a paz. A educação para a paz requer a educação em e para os Direitos Humanos, que ocorre através da criação de condições de paz:

A educação em direitos humanos não só é um complemento de aprimoramento na educação para a paz, mas que também é essencial para o desenvolvimento de capacidades para fazer a paz, e deve ser integrada a todas as formas de educação para a paz (REARDON, 2007, p. 62).

Como podemos perceber, educar em e para os Direitos Humanos, especialmente no Brasil, requer uma decisão, um esforço. Estamos passando por tempos complicados para se vivenciar os Direitos Humanos, e quando trazemos para a perspectiva de se educar em e para os Direitos Humanos sob a perspectiva do Bem Viver, os cenários ficam ainda mais restritos. Porém, desenvolver as mais diversas ações que fortaleçam as práticas de educar em e para os Direitos Humanos são de extrema importância.

\section{CONSIDERAÇÕES FINAIS}

Em nosso caminho acadêmico que vêm se desenhando há alguns anos, não acreditamos que o final de um texto acadêmico significa o final de uma exploração 
Epistemologia, ciência e saber na educação em/para os Direitos Humanos no Brasil: um olhar a partir do Bem Viver

científica. Nos finais de todos os nossos textos produzidos ficamos com a sensação e o dever que o caminho da construção científica ainda precisa ser trilhado, que não estamos no fim dos estudos, mas no caminho, pois a sociedade é dinâmica e vem mudando em ritmos que a ciência, especialmente as ciências sociais, precisam acompanhar constantemente.

A análise do presente texto se deu em analisar a educação em para os Direitos Humanos à luz do Bem Viver. Discorremos sobre a educação em e para os Direitos Humanos, seus conceitos, seus objetivos, seus direcionamentos. Entendemos que educar em e para os Direitos Humanos não se trata unicamente de uma disciplina (mesmo podendo se configurar como um componente curricular), mas sim de práticas de ensino formais e/ou informais que estimulem uma cultura em e para os Direitos Humanos. E pensar em educar nesse sentido passa por relembrar que a educação em e para os Direitos Humanos tem ligação estreita com os movimentos sociais. Os direitos alcançados são fruto do engajamento de grupos que lutaram e lutam por uma sociedade igualitária. Assim, pensar em educação em e para os Direitos Humanos também é perceber seu viés político. Se posicionar contra realidades de marginalização, buscando uma sociedade pautada na igualdade de direitos é uma decisão política. Não são práticas ingênuas e sem significados. E no tocante à realidade da América Latina, esse conteúdo político é forte. A história da América Latina é a história da colonização, mas é também a história da resistência. De luta contra a colonialidade do poder, como vimos.

Outro ponto que abordamos nesse capítulo de educação em e para os Direitos Humanos foi os desafios de pensar numa educação em e para os Direitos Humanos na atualidade. O cenário atual é muito próprio. Temos vivido em tempos em que a positivação dos direitos tem sido atacada por diversos grupos sociais. Nesse sentido, a educação em e para os Direitos Humanos nesse contexto tem como responsabilidade manter o acesso aos direitos, a educação em especial, como também ir no caminho de fortalecer a democracia através desse acesso.

Um elemento de destaque na educação em e para os Direitos Humanos na atualidade é o fortalecimento da democracia através da história. Os países latinoamericanos tem uma história de luta e resistência. É imprescindível que em tempos de regressos como estes que estamos vivendo, a memória se sobressaia nas

Educação, Psicologia e Interfaces, Volume 4, Número 3, p. 1-15, Julho, 2020.

ISSN: 2594-5343. DOI: $10.37444 /$ issn-2594-5343.v4i3.259 
práticas. Lembrar os caminhos percorridos enquanto coletividade colonizada, as lutas vividas, as opressões sofridas e as violências submetidas é um caminho para se lembrar os lugares que não podemos mais voltar. Essa postura assume-se contra hegemônica.

Tal abordagem se faz também através de uma educação para a paz. Educar em e para os Direitos Humanos através do resgate da memória se faz com o objetivo de se promulgar uma paz. Essa busca por vivência harmônica dialoga muito com a ideia do Bem Viver. Logo, percebemos o quanto uma educação em e para os Direitos Humanos pode ser instrumento eficaz na cultura de uma vivência pautada no Bem Viver, que busca essa forma de vida equilibrada entre as mais diversas formas de vida. Refletir sobre as bases epistemológicas da educação em e para os Direitos Humanos no contexto da América Latina, como também do Brasil nos fez perceber que o Bem Viver em muito pode dialogar com as práticas educativas percebidas na educação em e para os Direitos Humanos. São dois elementos que em muito se aproximam e que em muito podem contribuir na construção de uma sociedade harmônica e equilibrada. Sigamos então na busca por uma educação em/para os Direitos Humanos que busca uma vida digna para todas as formas de vida.

\author{
Notas de rodapé \\ ${ }^{1}$ Para aprofundar nas questões de Educação Popular ver: Brandão (2015); Freire (1981, 1985, 1987, 1997, \\ 2001); Carrillo (2010); Melo Neto (2015)
}

\title{
REFERÊNCIAS BIBLIOGRÁFICAS
}

APPOLINÁRIO, F. Metodologia da ciência: filosofia e prática da pesquisa. 2 ed. São Paulo: Cengage Learning, 2012.

BARROS, A. J. da S.; LEHFELD, N. A. de S. Fundamentos de Metodologia Científica. 3 ed. São Paulo: Pearson Prentice Hall, 2007.

BRANDÃO, C. R. Nós, os humanos: do mundo à vida, da vida à cultura. São Paulo: 
Epistemologia, ciência e saber na educação em/para os Direitos Humanos no Brasil: um olhar a partir do Bem Viver

Cortez, 2015.

CANDAU, V. M. Educação em direitos humanos: desafios atuais. In: SILVEIRA, R. M. G. et al. Educação em Direitos Humanos: fundamentos teórico-metodológicos. João Pessoa: Editora Universitária, 2007, p. 399-412.

CANDAU, V. M.; SACAVINO, S. Educação em Direitos Humanos: concepções e metodologias. In: FERREIRA, L. de F. G. et al. (org.). Direitos Humanos na Educação Superior: subsídios para a educação em Direitos Humanos na Pedagogia. João Pessoa: Editora Universitária da UFPB, 2010, p. 113-140.

CARBONARI, P. C. Porque educação em direitos bases para a ação político-pedagógica. In: RODINO, A. M. et al. (orgs.). Cultura e Educação em Direitos Humanos na América Latina. João Pessoa, CCTA, 2016, p. 251-275. Disponível em: < http://www.cchla.ufpb.br/ncdh/wpcontent/uploads/2016/07/EBOOK-Cultura-e-EDH- Am\%C3\%A9rica-Latina_Miolo_0205-16.pdf>. Acesso em: 03 jun. 2019.

CARRILlO, A. T. Educación Popular y Producción de Conocimiento. Revista La Piragua, n. 32, p. 8-25, 2010.

FERNÁNDEZ, B. Educación popular y "buen vivir": interacciones en lo pedagógico. Revista Internacional sobre Investigatión en Educación Global y para el Desarrollo, n. 10, p. 15- 28, 2016.

FREIRE, A. M. A. (org.). A pedagogia da libertação em Paulo Freire. São Paulo: Unesp, 2001.

FREIRE, P. Educação e mudança. 4 ed. Rio de Janeiro: Paz e Terra, 1981.

FREIRE, P. Pedagogia da autonomia: saberes necessários à prática educativa. São Paulo: Cortez, 1997.

FREIRE, P. Pedagogia do oprimido. 17 ed. São Paulo: Paz e Terra, 1987.

FREIRE, P. Reflexión crítica sobre las virtudes del educador. Buenos Aires: Mimeo, 1985.

HOUAIS, A. Dicionário Houaiss da Língua Portuguesa. Rio de Janeiro: Objetiva, 2001.

LARREA, A. M. El buen vivir como alternativa civilizatória. In: ENDARA, G. Postcrecimiento y buen vivir: propuestas globales para la construcción de sociedades equitativas y sustentables. Quito: Friedrich-Ebertstiftung (FESILDIS), 2014.

LIMA, M. F. S. de; SILVEIRA, R. M. G. Educação em/para os Direitos Humanos: justificando os porquês. In: ANDRADE, F. C. B. de; RECHEMBACH, F. (orgs.). Educação em Direitos Humanos: construindo políticas públicas. Curitiba: CRV, 2017.

Educação, Psicologia e Interfaces, Volume 4, Número 3, p. 1-15, Julho, 2020.

ISSN: 2594-5343. DOI: 10.37444/issn-2594-5343.v4i3.259 
MARCONI, M. de A.; LAKATOS, E. M. Técnicas de pesquisa. 8 ed. São Paulo: Atlas, 2017.

MELO NETO, J. F. de. Educação Popular: enunciados teóricos. João Pessoa: Editora do CCTA, UFPB, 2015.

MINAYO, M. C. de S. (org.). Pesquisa social, teoria, método e criatividade.

29 ed. Petrópolis, RJ: Vozes, 1994.

PALUDO, C. Educação Popular: dialogando com redes latino-americanas (20002003). In: PONTUAL, P; IRELAND, T. (orgs.). Educação Popular na América Latina: diálogos e perspectivas. Brasília: Ministério da Educação, UNESCO, 2006, p. 41-61.

REARDON, B. A. Direitos humanos como educação para a paz. In: CLAUDE, R. P.; ANDREOPOULOS, G. (orgs.). Educação em direitos humanos para o século XXI. São Paulo: Editora da Universidade de São Paulo, 2007.

RODINO, A. M. La institucionalización de la educación en derechos humanos en los sistemas educativos de América Latina (1990 - 2012): avances, limitaciones y desafios. In: RODINO, A. M. et al (orgs.). Cultura e educação em direitos humanos na América Latina. João Pessoa: CCTA, 2016, p. 90-123.

SILVEIRA, R. M. G. Educação em Direitos Humanos e Currículo. In: FLORES, E. C. et al (orgs.). Educação em Direitos Humanos \& Educação para os Direitos Humanos. João Pessoa: Editora da UFPB, 2014, p. 77-91.

SILVEIRA, R. M. G. Educação em/para os Direitos Humanos: entre a universalidade e as particularidades, uma perspectiva histórica. In: SILVEIRA, R. M. G. et al. (orgs.). Educação em Direitos Humanos: fundamentos teórico-metodológicos. João Pessoa: Editora Universitária, 2007, p. 245-273.

TOSI, G. O que são e quando surgem os direitos humanos: aproximações conceituais. In: ANDRADE, F. C. B. de; RECHEMBACH, F. (orgs.). Educação em Direitos Humanos: construindo políticas públicas. 1 ed. Curitiba: CRV, 2014, v. 1, p. 21-45.

VIOLA, S. E. A.; PIRES, T. V. Educação em direitos humanos e sociedade: para além do liberalismo. In: RODINO, A. M. et al. (orgs.). Cultura e Educação em Direitos Humanos na América Latina. João Pessoa, CCTA, 2016, p. 181-200. Disponível em: < http://www.cchla.ufpb.br/ncdh/wp-content/uploads/2016/07/EBOOK-Cultura-e-EDHAm\%C3\%A9rica-Latina_Miolo_02-05-16.pdf>. Acesso em: 03 jun. 2019.

\section{Credenciais da/os autora/es}

Educação, Psicologia e Interfaces, Volume 4, Número 3, p. 1-15, Julho/Setembro, 2020. ISSN: 2594-5343. DOI: 10.37444/issn-2594-5343.v4i3.259 

partir do Bem Viver

MELO, Natália de Oliveira. Professora substituta na Universidade Federal de Pernambuco, graduada em Pedagogia (UFPE), Mestre em Direitos Humanos, Cidadania e Políticas Públicas (UFPB). E-mail: oliveiramelonatalia@hotmail.com

IRELAND, Timothy Denis. Professor titular da Universidade Federal da Paraíba. Possui graduação em Letras e Língua Inglesas (English Language and Literature) pela Universidade de Edimburgo (1971), mestrado em Educação de Adultos - Universidade de Manchester (1978) e doutorado em Educação de Adultos - Universidade de Manchester (1988). Atualmente é professor dos programas de pós-graduação em educação (PPGE) e em Direitos Humanos, Cidadania e Políticas Públicas (PPGDH) e coordenador da Cátedra da UNESCO em Educação de Jovens e Adultos.

Endereço para correspondência: Natália de Oliveira Melo. Rua Gonçalo Coelho, 551, Maurício de Nassau, 55014-020, Caruaru/PE. E-mail: oliveiramelonatalia@ hotmail.com

Como citar este artigo (Formato ABNT): MELO, Natália de Oliveira; IRELAND, Timothy Denis. Epistemologia, ciência e saber na educação em/para os Direitos Humanos no Brasil: um olhar a partir do Bem Viver. Educação, Psicologia e Interfaces, v. 4, n.3, p. $1-15,2020$.

Recebido: 03/04/2020.

Aceito: 20/05/2020.

Educação, Psicologia e Interfaces, Volume 4, Número 3, p. 1-15, Julho, 2020.

ISSN: 2594-5343. DOI: 10.37444/issn-2594-5343.v4i3.259 